\title{
La traducción en la obra de Carmen Martín Gaite
}

\section{Translation in the Work of Carmen Martín Gaite}

\author{
Mónica FUENTES DEL Río \\ Investigadora independiente \\ monicafuentesrio@yahoo.es
}

Recibido febrero-2019. Revisado: marzo-2019. Aceptado: mayo-2019.

Resumen: Una de las facetas creadoras de la escritora Carmen Martín Gaite es su labor como traductora. Tradujo del italiano, portugués, francés e inglés, aunque comenzó haciéndolo del rumano durante su formación universitaria. Compaginó sus traducciones con sus reflexiones sobre el arte de traducir, que forman parte de su teoría literaria, expuesta de manera fragmentaria en ensayos, críticas literarias, artículos periodísticos, conferencias y cuadernos. Y simultaneó su labor traductora y su poética con su práctica ficcional, sus críticas literarias, sus ensayos, sus investigaciones históricas, etc. Todas estas facetas creadoras se influyen mutuamente, al igual que ocurre con su teoría literaria. La autora reflexionó sobre el concepto de traducción, como recreación o interpretación del texto, aunque siempre respetando la obra original; la labor del traductor y los requisitos necesarios para ejercerla; el arte de traducir y la traducción en la sociedad actual.

Palabras clave: Carmen Martín Gaite; traducción; teoría literaria; práctica ficcional.

Abstract: One of the creative facets of the writer Carmen Martín Gaite is her work as a translator. She translated from Italian, Portuguese, French and English, although 
she started doing it from Romanian during her university education. She combined her translations with her reflections on the art of translating, which are part of her literary theory, exposed in a fragmentary manner in her essays, literary criticism, journalistic articles, lectures and notebooks. And she combined her work as a translator and her literary theory with her fictional practice, her literary critiques, her essays, her historical investigations, etc. All these creative facets influence each other, as happens with her literary theory. The author reflected on the concept of translation, as recreation or interpretation of the text, although always respecting the original work; the work of the translator and the necessary requirements to perform it; the art of translation and translation in today's society.

Key words: Carmen Martín Gaite; translation; literary theory; fictional practice.

La traducción es uno de los numerosos aspectos sobre la concepción de la literatura, considerada un acto comunicativo, que Carmen Martín Gaite (1925-2000) elaboró durante cerca de cincuenta años en sus ensayos, críticas literarias, artículos periodísticos, conferencias y anotaciones de sus «cuadernos de todo», que era como la autora de la denominada generación del medio siglo llamaba a sus cuadernos, en los que escribió y trabajó a lo largo de su vida. La escritora compaginó con sus distintas facetas creadoras sus reflexiones sobre la literatura, la escritura y el arte de narrar, que constituyen una teoría literaria, reflejada y originada, en gran medida, por su práctica ficcional -novelas, cuentos, teatro y poesía-, de modo que ambas se retroalimentan e influyen mutuamente, lo cual confiere un carácter circular al conjunto de su producción y pensamiento (Fuentes del Río 2017).

\section{LA TRADUCCIÓN EN LA TEORÍA LITERARIA DE CARMEN MARTÍN GAITE}

Durante su trayectoria creadora Carmen Martín Gaite reflexionó sobre la literatura, el arte de narrar, la escritura, la crítica literaria, la lectura, la fe en la palabra y el logos, la obra literaria, la traducción, etc. Como hizo con la escritura y la crítica literaria, la autora disertó sobre el concepto de la traducción, la labor del traductor, las cualidades y los requisitos del traductor, el arte de traducir y la traducción en la sociedad actual.

\subsection{La traducción o versión: la recreación del texto}

Para Martín Gaite, la traducción o versión es una interpretación de la obra original, aunque debe ser fiel y respetuosa con el libro del que procede, sin mejorarlo ni tampoco estropearlo. Por ejemplo, respecto a la traducción de la novela El amante de 
Lady Chatterley, la novela del autor D. H. Lawrence, escribe: «Hay que agradecer a Bernardo Fernández una traducción muy fiel, que no ha tratado de embellecer el texto ni de limar sus defectos» (Martín Gaite 2006, 326).

La elaboración de la traducción o versión conlleva la lectura o interpretación de la obra y su escritura. El traductor, por tanto, cumple la doble condición de lector y de creador, como le ocurre al crítico, aunque, en este caso, se trata de una recreación del texto original a otra lengua. Al igual que el crítico, el traductor debe hacer una lectura en profundidad: el primero, para analizarla, escribir y crear un nuevo texto, una crítica, sobre la obra; y el segundo, para escribirla en otra lengua, recrearla. La lectura que debe hacer el traductor es, incluso, mucho más exhaustiva y minuciosa que el crítico (Fuentes del Río 2017).

\subsection{La labor del traductor}

La importancia que la autora concede a la labor del traductor o de la traducción de las obras se refleja en sus usuales referencias a las versiones que lee para elaborar sus críticas literarias. Es más: dedica, incluso, un artículo periodístico a la traducción, «La ingrata condición del traductor. Bailar con la más fea», que publica en Diario 16 el 24 de julio de 1978 (Martín Gaite 2006, 192-194). Es evidente que su propia práctica como traductora avala la relevancia que otorga a este trabajo. $Y$ lo hace siempre con la preocupación por el respeto a la obra original y la recepción por parte del lector de dicho libro.

Al igual que el escritor o el crítico literario, la labor del traductor requiere el cumplimiento de unos requisitos para su adecuado ejercicio. El principal es el conocimiento de la lengua, en especial, de aquella a la que se traduce la obra. En este sentido, Martín Gaite es un ejemplo de sus propias reflexiones sobre la traducción, ya que era una profunda conocedora y aficionada a la lengua española y también a otros idiomas. Teruel, en su edición del libro Tirando del hilo (artículos 1949-2000), que incluye dicho artículo, comenta en una nota la existencia de un manuscrito de la autora, posterior a 1978, destinado a una disertación oral sobre la traducción. En los paréntesis aclaratorios de este original, la escritora se refiere al conocimiento exhaustivo del idioma al que se traduce o se vierte la obra original como el principal requisito en la labor del traductor.

En general creo que es mejor ser totalmente experto en el idioma al que se vierte el texto que en aquel en que está escrito, y de hecho la repugnancia que nos invade al leer una mala traducción se concreta en comentarios como: «iPero esto no suena a castellano!». Si uno tarda en releer una traducción que ha hecho el tiempo suficiente como para sentirla ajena, puede considerarse un éxito que nada te disuene como giro extranjero (Martín Gaite 2006, 193). 
En ese mismo manuscrito sobre la traducción, según explica Teruel en una nota, la autora destaca las cuatro etapas del proceso de traducción, lo cual nos acerca a su propia labor como traductora, ya que la alusión a estrenar un cuaderno de limpio es característica de Martín Gaite, metáfora de la íntima conexión entre este trabajo y la creación literaria.

Seguidamente señala cuatro etapas en el proceso de traducción: «1. ${ }^{a}$ Leer el texto en el idioma original y empaparse de él, olvidando que se va a traducir. 2. ${ }^{a}$ Anotar las palabras difíciles en una segunda revisión. 3. ${ }^{a}$ Leerlo ya de corrido con ojos de traductor y apuntar diversas opciones para resolver los giros difíciles. Y $4 .{ }^{a}$ Estrenar un cuaderno de limpio» (Martín Gaite 2006, 193).

La autora reconoce las dificultades que supone traducir determinadas obras, en especial, debido a las diferencias entre las dos lenguas -la original y aquella a la que se traduce el libro-, ya que, en ocasiones, es complejo mantener el estilo del escritor. «En definitiva, los problemas que plantea la traducción son bastante análogos a los que plantea la escritura: se trata de ponerse en la piel del lector y conseguir hacerle ver lo que uno ve y desde donde lo ve» (Martín Gaite 2006, 193).

Siempre que he tenido una traducción -labor de buenos traductores, desde luego-, he experimentado una gran satisfacción. Pero, mira, quizá no tanta como al saber que soy leída en mi lengua. Yo misma he sido traductora y sé que algo se pierde en el camino. Yo utilizo mucho un lenguaje coloquial; mis textos tienen un humor verbal que quizá pierde algo de su fuerza al ser traducido. He hablado de ello con colegas a los que les entusiasma que se les traduzca; a mí, me gusta, pero prefiero que se me lea en español (Martín Gaite en Martinell Gifre 1998).

De sus reflexiones sobre el proceso y la labor de traducir se pueden deducir las analogías con el oficio de escribir o crear ficción. En este sentido, muchas de las ideas sobre el escritor y la creación literaria son extensibles al traductor y su trabajo. Una de las mayores dificultades para el traductor es el respeto a la obra original, en especial, al estilo del escritor traducido y también a otros elementos clave de la historia, según anota ella misma en el manuscrito original de la mencionada disertación oral dedicada a la traducción. «Dos puntales importantes me parecen el humor y los diálogos, cuyo traslado tiene que encontrar la diana apropiada en nuestro idioma» (Martín Gaite 2006, 193). Además, resulta difícil traducir de forma fiel al original la poesía y el singular estilo de determinados escritores, como Natalia Ginzburg, con la que compartía numerosas afinidades.

El estilo de la Ginzburg, totalmente despojado de hojarasca ornamental, ofrece para el traductor todas las dificultades de lo aparentemente banal, cuando es profundo. 
Podría aplicársele aquella copla de Bergamín: «Eres como el agua quieta, / tan clara, que vuelve oscuro / todo lo que transparenta». En el caso del libro que nos ocupa, las dificultades se acrecientan además por la peculiaridad de un léxico «solo para iniciados». Por eso es de agradecer la impecable versión de Mercedes Corral (Martín Gaite 2006, 424).

\subsection{El arte de traducir}

Con frecuencia, en sus críticas literarias, Martín Gaite alude al trabajo del traductor, ya sea para censurarlo o para alabar su esmero, el cual está íntimamente vinculado a la pasión por el texto y por su labor, como en el caso del escritor.

Acaba de aparecer, editada por La Gaya Ciencia, una versión bilingüe de Les fleurs du mal, a cargo del poeta Antonio Martínez Sarrión. La traducción, esquivando la aventura arriesgada y casi imposible de conservar la rima, se ha atenido a un criterio más honesto y riguroso dictado, simplemente, por un acendrado amor al texto y presidido por una clara voluntad de desagravio a Charles Baudelaire, tan maltratado hasta hoy por los traductores españoles, como el propio Sarrión señala en el prólogo. Así, respetando únicamente el ritmo y la métrica, Martínez Sarrión, tras nueve meses de dedicación intensiva y huyendo en todo momento del lucimiento personal, nos ofrece un magnífico resultado que cumple de forma definitiva su propósito de hacer tardía justicia al poeta francés: han quedado borrados para siempre los agravios. [...] la traducción de Martínez Sarrión ha logrado transmitirnos, en toda su exquisita mezcla de pureza e impureza originales, el hechizo, la fascinación y la perfidia que aroman estas flores cultivadas por el primer jardinero del mal (Martín Gaite 2006, 164-165).

El rigor, el respeto o la fidelidad a la obra original y la capacidad de transmitir los sentimientos y las sensaciones de esta son algunas de las cualidades positivas que alaba Martín Gaite sobre las traducciones, de las que destaca el esmero y el mimo de la labor del traductor: «una esmerada versión de Francisco Perujo» de la primera novela de Italo Svevo Una vida, publicada por Barral Editores (Martín Gaite 2006, 183). Incluso, ensalza la delicadeza del traductor, imprescindible para traducir determinadas obras. Por ejemplo, en la traducción de Cartas a Felice, del escritor Franz Kafka: «Pablo Sorozábal Serrano ha vertido al castellano las quintaesencias y contradicciones del enamorado con un esmero y una delicadeza verdaderamente dignas de aplauso» (Martín Gaite 2006, 152-153).

La honestidad y el respeto al trabajo de los traductores por parte de Martín Gaite se refleja también en sus comentarios sobre las traducciones, ya que cuando cree que se trata de una mala labor, salvo excepciones, no suele mencionar el nombre 
del traductor, algo que sí hace siempre cuando alaba las traducciones que considera buenas. Sin embargo, censura abiertamente el mal trabajo, por sus perjudiciales consecuencias respecto a la lectura de la versión de la obra original y de su autor, en especial, si ambos destacan por su calidad. Como en el arte de narrar, el arte de traducir requiere esmero, dedicación y pasión, sobre todo, para superar las dificultades de la traducción de determinadas obras.

Es una lástima que la primera novela de Carlos Semprún-Maura que podemos leer en castellano casi no la podamos leer. L'an prochain à Madrid -cuya traducción correcta hubiera sido: Al año que viene, en Madrid-merecía, a mi juicio, mejores tratos que los que ha recibido en esta versión, desganada y sin aliento, que nos presenta Monte Ávila Editores, y que roza lo inaceptable. No se me oculta que era un libro difícil de traducir no solo porque la mayor eficacia expresiva residía en la justeza de los diálogos, sino también porque casi todas las evocaciones del narrador, español de origen, exiliado con sus hermanos, su padre y su madrastra a raíz de la guerra civil, remiten a su infancia madrileña y a sus furtivos regresos desde Francia, en los años cincuenta, como militante clandestino. Dado, pues, que el Madrid de anteguerra y de posguerra es un leitmotiv recurrente y fundamental, se ponen más de relieve la torpeza y la falta de esmero de la labor para recrear un ambiente y un lenguaje tan concretos (Martín Gaite 2006, 184).

La falta de esmero y de rigor en la labor del traductor repercute de manera negativa en la percepción y aprehensión de la obra original y del estilo literario propio del escritor por parte del lector durante el proceso de lectura de la traducción, hasta el punto de que en este caso Martín Gaite recurre al libro en francés para elaborar su crítica, gracias a su profundo conocimiento de dicho idioma.

Y repito que es una pena, porque Carlos Semprún-Maura había acertado a contar la historia en francés -su lengua adoptiva- con una mezcla de despego y de contenida emoción que recuerdan al mejor Camus, al de El extranjero. Sobre esa edición original (París, Julliard, 1975) voy a elaborar mi comentario; no puedo, en rigor, hacer otra cosa (Martín Gaite 2006, 184).

La autora critica, a veces, con ironía y sarcasmo, la falta de rigor en la labor traductora, por los perjuicios que supone para el lector. En su crítica literaria sobre El príncipe negro, de la narradora irlandesa Iris Murdoch, afirma que está «traducida, por desgracia, horriblemente mal, por una tal Camila Batlles, a quien evidentemente no ha llamado Dios por el camino del rigor ni del esmero» (Martín Gaite 2006, 154). En otras ocasiones, la censura a las traducciones se basa en el escaso dominio de la lengua a la que se traduce la obra. En una crítica literaria a la publicación del diario de Katherine Mansfield, asegura que está «traducido ahora a un castellano deficiente por Ediciones 
Del Cotal» (Martín Gaite 2006, 278). Como crítica, escritora y traductora, es exigente, ya que siempre desempeña estas facetas pensando en el lector. Y así lo demuestran sus comentarios al respecto. Sobre la biografía de Virginia Woolf escrita por Quentin Bell, afirma: «Al éxito de esta publicación contribuye, sin duda, la estupenda traducción de Marta Pessarrodona, enturbiada tan solo por los dichosos es por eso que... de que no aprenden a prescindir los catalanes» (Martín Gaite 2006, 261). Este comentario evidencia su profundo conocimiento también del español y del inglés.

\subsection{La traducción en la sociedad actual}

El esmero con que desempeña sus distintas facetas creadoras, entre ellas, la de traductora, contrasta con la opinión de la sociedad actual sobre la traducción y el traductor, cuya labor resulta ingrata.

Resulta normal oír ensalzar -a veces, a decir verdad, con una retórica un tanto cargante- la vocación empedernida del escritor que, desperdiciando otros trabajos más remunerativos, lucha por dar forma a los confusos fantasmas que se aglomeran en su cerebro, sin preocuparse demasiado del estipendio que va a recibir por esa lealtad a un quehacer cuyo alcance resulta más que discutible. Pero yo personalmente encuentro mucho más meritoria, casi me atrevería a llamarla heroica, la vocación del traductor, cuyas fatigas como artífice de la palabra requiere la misma delicadeza e incluso mayor rigor para alcanzar un resultado satisfactorio, con la diferencia de que los riesgos y sacrificios de esta labor casi nunca son reconocidos por nadie y ofrecen bien pobres compensaciones para quien la emprende con entusiasmo. Hasta el punto de que uno se pregunta cómo podrán existir -aunque sean pocos- algunos traductores vocacionales. [...] Pero ¿y los traductores qué? ¿Quién se acuerda de los traductores, quién piensa en los escollos de su trabajo, quién los guía, quién los ensalza, enseña o estimula? ¿Qué incentivos tienen para esmerarse en su labor? Bien lejos quedan aquellos tiempos de Alfonso X el Sabio y de la escuela de traductores de Toledo, considerados y respetados como artistas que eran (Martín Gaite 2006, 192-193).

La escasa importancia que concede la sociedad actual a la labor de los traductores contrasta también con la relevancia que concede Martín Gaite a la traducción, como demuestran sus críticas literarias.

Hace poco, en estas mismas páginas, apareció un artículo, que probablemente no tuvo eco alguno, donde se daba, con amargura, la noticia de que este año hasta el premio Fray Luis de León se les iba a escatimar -por falta de presupuesto- a los buenos traductores como galardón a su esfuerzo. Quien firmaba aquel artículo y emitía 
tales quejas era Esther Benítez, consagrada desde hace años de manera exclusiva a elaborar excelentes versiones del italiano y que se ha atrevido, sin embargo, con autores como Boccaccio, Alfieri, Gramsci, Moravia, Pavese, Calvino y Pasolini. Actualmente la editorial Alfaguara acaba de publicar una edición de Los novios de Manzoni a cargo de esta notable profesional de la traducción, a quien con este motivo ya es hora de rendir públicamente justicia. No sé lo que habrá percibido Esther Benítez como pago a su trabajo, pero desde ahora afirmo que todo lo que le hayan dado se lo merece. [...] el aliento de Esther Benítez para emprender la tarea -acompañada de introducción, bibliografía y notas - corre pareja con la maravilla del resultado, digno de ovación (Martín Gaite 2006, 193-194).

El esmero y el trabajo bien hecho en la traducción realzan aún más la calidad de la obra traducida, como asegura Martín Gaite, respecto a la novela emblemática de Manzoni.

Lo mismo podría decirse de la versión que recientemente ha ofrecido otra veterana de la traducción, Consuelo Bergés, de La cartuja de Parma de Stendhal en Alianza Editorial.

En ambos casos puedo afirmar -porque conozco las dos obras en su lengua original- que hay que descubrirse ante estas mujeres, para quienes traducir no es un lujo o una dedicación accesoria y excepcional, sino aquella que han elegido y en la que se mantienen contra viento y marea. Su contribución a las letras es impagable (Martín Gaite 2006, 194).

Como asegura la autora, en la sociedad actual no es habitual la labor de los buenos traductores, que requiere esmero y precisión; en alusión al traductor de la obra El futuro de la novela, afirma: «Diré para terminar que el prólogo de Roberto Yahni es un completo acierto y que ha traducido los textos de Henry James en una prosa de gran belleza, con un esmero y una precisión a que no estamos acostumbrados» (Martín Gaite 2006, 55). La escritora se muestra crítica con el sector editorial español, responsable del descuido de las traducciones de los escritores.

A partir de Cesare Pavese (1908-1950), la narrativa italiana, influida en muchos aspectos por este gran escritor, ha venido dando unos frutos de alta calidad, aunque no se puede apelar como garantía de mi opinión al aprecio y al éxito que han conseguido en su exportación al mercado extranjero. Tal es el caso, por ejemplo, de Natalia Ginzburg, perteneciente, como Pavese, al grupo torinés de la editorial Einaudi y que, a pesar de ser una escritora tan importante como pueda serlo Virginia Woolf, aún no ha merecido una traducción decente al castellano de ninguna de sus novelas (Martín Gaite 2006, 170). 


\section{LA LABOR TRADUCTORA DE CARMEN MARTÍN GAITE}

Los frecuentes comentarios de la autora sobre la traducción de las obras extranjeras que reseña en sus críticas literarias reflejan su propio quehacer como traductora y su extraordinario dominio de los idiomas. Sus viajes contribuyeron al conocimiento y perfeccionamiento de diferentes lenguas y le permitieron descubrir la obra de los escritores más importantes de las distintas tradiciones literarias, algunos de los cuales fueron muy influyentes en su obra. En el verano de 1946, le concedieron su primera beca de estudios para viajar fuera de España, en concreto, para la universidad portuguesa de Coimbra; y dos años después la segunda, esta vez para la francesa Cannes (Martín Gaite 1993, 17). A mediados de los años cincuenta, tras casarse, pasó varios meses en Italia y también viajó a París (Martín Gaite 1993, 20); y a partir de 1979 fue en numerosas ocasiones a Estados Unidos y a Europa invitada por diversas universidades, debido a la repercusión de su labor como escritora, o por la traducción de sus novelas en dichos países. Además, su formación universitaria -estudió Filología Románica-, su afán autodidacta, su natural curiosidad por el conocimiento y el aprendizaje, su profundo respeto por la palabra, el contacto con el grupo de Madrid de la generación del medio siglo y sus propios padres -tanto dichos escritores como su entorno familiar facilitaron su acceso a diversas lecturas- posibilitaron que adquiriera un bagaje cultural y literario excepcional, esencial no solo en su formación de escritora, sino también en otras facetas creadoras, por ejemplo, en su labor como traductora y crítica literaria (Fuentes del Río 2019). A lo largo de su vida enriqueció este acervo con sus variadas lecturas, ya que desde niña era una lectora contumaz.

\subsection{Carmen Martín Gaite como traductora}

Profesionalmente, Martín Gaite tradujo al español por encargo obras escritas en italiano, portugués, francés e inglés ${ }^{1}$. Sin embargo, comenzó a traducir durante su época de estudiante universitaria, en concreto, del rumano. Como explica Calvi (2007, 15-16), entre 1947 y 1950 publicó en la revista Trabajos y días tres poemas, dos cuentos y algunas traducciones del poeta rumano Tudor Arghezi, unos textos recopilados por Romero López (2002). Por su parte, Fernández Hoyos $(2014,113)$ considera que quizá se debiera al profesor rumano Aurelio Rauta, que impartía clase de dicho idioma en la Facultad de Letras salmantina, donde estudiaba la autora.

1. La autora también tenía conocimientos del gallego, por su ascendencia materna. De hecho, veraneó durante su infancia y primera juventud en la aldea orensana de San Lorenzo de Piñor. 
Su primera traducción profesional fue Vino y pan (1968), del autor italiano Ignacio Silone; y la última publicada, la obra portuguesa Cartas de amor de la monja portuguesa Mariana Alcoforado (2000). Durante ese período de tiempo, además, tradujo del italiano, Corto viaje sentimental y Senectud (Italo Svevo), El sistema periódico e Historias naturales (Primo Levi), y Querido Miguel y Nuestros ayeres (Natalia Ginzburg); del portugués, El misterio de la carretera de Sintra (Eça de Queirós y Ramalho Ortigão) y El marinero (Fernando Pessoa) -se trata de una versión de la obra original para su representación teatral-; del francés, Cuentos de hadas (Charles Perrault), Madame Bovary (Gustave Flaubert), Cartas francesas a Merline (Rainer Maria Rilke) y El hombre acostado (Carlos Semprún Maura); y del inglés, Actitudes patriarcales (Eva Figes), Al faro (Virginia Woolf), Cumbres borrascosas (Emily Brontë), El cuervo (Edgar Allan Poe) -en colaboración con Francisco Cumpián y Antonio Bueno Tubia-, Viaje hacia el amor y otros poemas (1954-1962) (Williams Charles William), Una pena observada (C. S. Lewis), Cuentos españoles de antaño (Felipe Alfau), Cuentos de hadas victorianos (varios autores), La princesa y los trasgos (George MacDonald) y Jane Eyre (Charlotte Brontë)2 $)^{2}$ Cuando está ultimando la traducción de esta última novela, la propia autora asegura: "casi todo lo que traduzco son obras de mujeres" (Martín Gaite en Berasátegui 2000, 29). Precisamente la mujer es uno de los motivos temáticos habituales tanto en su obra literaria, como en sus ensayos sobre la literatura -a la relación entre la ficción y la mujer dedica algunos textos, como el ensayo Desde la ventana-.

Durante su trayectoria Martín Gaite no «ha dejado nunca de traducir, como si el ejercicio de acercarse a la escritura de otro fuera un acicate más para su propia creación» (Martinell Gifre 1999, 25). Este mismo comentario se podría aplicar a otras facetas, como la crítica literaria, los ensayos, su ficción, su labor de prologuista y los comentarios anotados en los "cuadernos de todo" sobre sus lecturas, en el continuo diálogo que mantenía con otros autores, mediante sus libros. Esta idea está relacionada con el concepto que tiene Martín Gaite sobre la lectura como diálogo entre el lector y el escritor, a través de su obra (Fuentes del Río 2017).

Gracias a su labor como traductora descubrió a algunos autores o los conoció en profundidad. Por ejemplo, la novela Jane Eyre, de Charlotte Brontë, de la que, cuando estaba finalizando su traducción, asegura en una entrevista: «nunca creía que era tan buena novela» (Martín Gaite en Berasátegui 2000, 29). Otro ejemplo es A grief observed, de C. S. Lewis, cuyo descubrimiento e importancia en la vida de Martín Gaite destaca González Couso (2009).

En las últimas páginas del estudio preliminar a su traducción de La princesa y los trasgos, Martín Gaite hace un paréntesis en la explicación de la influencia de MacDonald

2. La relación de obras traducidas se ha realizado contrastando estas dos fuentes: Martinell Gifre (1997, 79-82) y Jurado Morales (2003, 473-474). 
en C. S. Lewis: "Diré, de pasada, y para seguir este hilo raro que nos une a unos escritores con otros, que yo descubrí a C. S. Lewis por casualidad hace diez años, en momentos muy malos de mi vida ${ }^{3}$, y que su libro A grief observed fue también para mí una especie de bautismo» (p. 43) (González Couso 2009).

Otro ejemplo es Virginia Woolf. Durante su estancia en Nueva York en el otoño de 1980, Martín Gaite leyó A room of one's own, de esta autora, cuya novela Al faro había traducido durante el verano de ese año. Antes, en 1977, había leído ya su ensayo sobre el quehacer literario titulado La torre inclinada, del que escribió una crítica literaria, publicada ese año (Martín Gaite 2006, 149-150), y en 1979 elaboró una crítica sobre la biografía acerca de Virginia Woolf (Martín Gaite 2006, 260-261). En 1980 comenzó a escribir sus experiencias en la ciudad estadounidense. Se trata de un cuaderno de collages titulado Visión de Nueva York (Martín Gaite 2005), cuya primera anotación está fechada el 17 de septiembre. En sus primeros apuntes la autora confiesa su fascinación y admiración por Nueva York, ciudad que ya visitó en 1979 y a la que volvería durante los siguientes años invitada por varias universidades estadounidenses. Además, dedica las primeras páginas del cuaderno a la obra de Virginia Woolf y a la lectura de A room of one's own. También escribirá sobre ella en otros textos, como en el ensayo sobre literatura y mujer Desde la ventana.

Aquí a la gente le extraña bastante que yo haya traducido To the lighthouse [Al faro] de la Woolf. Me acuerdo de todas las horas que le dediqué en el Boalo a esa traducción, de las resonancias que allí, en el despacho de papá, me traía ese texto. Hace solo mes y medio. Ahora-también el otro día en Rizzoli- he comprado A room of one's own, que he terminado de leer este fin de semana en New Haven y que me congracia con la Woolf ya definitivamente (Martín Gaite 2005, 27).

El esmero que exigía Martín Gaite al trabajo del traductor, tal como ella misma alababa en sus críticas literarias, se encuentra en su labor como traductora. Así se refleja en las alabanzas de los críticos literarios a sus traducciones, de las que han destacado, por ejemplo, que «ha sabido volcar intacto, y casi diríamos que con pureza, el intimismo de Natalia Ginzburg al español sin perder su tensión», como asegura Pedro Corral, en alusión a su versión de Querido Miguel, publicada en 1989, que Diario de Mallorca considera una «traducción de lujo». No en vano era una gran conocedora de la lengua castellana y de los idiomas de los que traducía, a lo que hay que añadir su

3. Cuando Martín Gaite traduce este libro, su hija había fallecido recientemente, en 1985. C. S. Lewis escribió esta obra tras la enfermedad y el fallecimiento de la escritora estadounidense Helen Joy Davidson Gresham, profunda admiradora del autor británico. Esta historia fue llevada al cine por Richard Attenborough bajo el título Tierras de penumbra.

La traducción en la obra de Carmen Martín Gaite Mónica FUENTES DEL RIOO 
maestría como escritora. Respecto a esta obra, la crítica literaria ha resaltado, incluso, su influencia en su novela Nubosidad variable, cuyo proceso de escritura coincide con dicha traducción. Aparte de que las dos autoras compartían un universo y una forma de escribir -de modo fragmentario- cercanos, estas dos obras son epistolares; en el caso de Nubosidad variable, son dos mujeres las protagonistas. Así, como afirma Toni Montesinos $^{4}$, «el ritmo lento, el lenguaje coloquial, los numerosos diálogos, el análisis inocente de insignificancias diarias y el pensamiento femenino más íntimo pueblan sus páginas». Precisamente estos rasgos se encuentran también en la literatura y el estilo literario de Martín Gaite. De igual forma, la crítica literaria ha destacado su traducción de la novela Senectud, del escritor italiano Italo Svevo.

Gracias a la traducción certera efectuada por Carmen Martín Gaite, Senectud no ha perdido la vitalidad del original y se ha puesto al alcance del público lector más exigente del habla hispana. Hasta el más fino de los sentimientos es calibrado con admirable precisión, convirtiendo la novela en un agudo friso de las pasiones humanas. Svevo es uno de los escritores italianos más importantes e imprescindibles del siglo XX, y Senectud, una excelente oportunidad para corroborarlo5.

Su labor traductora fue reconocida de forma póstuma con la concesión del Premio Ángel Crespo por su traducción de la novela Jane Eyre, de Charlotte Brontë. Martín Gaite admite su intención de respetar las características de la obra original, tal como escribe en julio de 1974, en el prólogo a la primera edición de su traducción de El misterio de la carretera de Sintra, de los escritores portugueses Eça de Queirós y Ramalho Ortigão.

He querido respetar en la traducción, la frescura que tiene de apuntes o crónicas de urgencia para el público voraz que las esperaba, y solo en algunos casos me he atrevido a limar un poco los defectos del lenguaje. En cuanto al tono sombrío y posromántico de alguna de las descripciones finales, también lo he conservado lo mejor que he podido en mi versión al español, pensando que puede tener, cuando menos, un valor documental (Martín Gaite 2011, 15).

4. Estas tres críticas están recogidas por la página web de Acantilado, editorial a la que pertenece la última edición de la traducción de Martín Gaite de Querido Miguel (2000), de Natalia Ginzburg. La crítica de Pedro Corral fue publicada en $A B C$ y la de Toni Montesinos en La Razón, el 1 de septiembre de 2000.

5. Así lo asegura el crítico literario Augusto Munaro, en Sangría, de Chile, según la reseña publicada por la editorial Acantilado en su página web. 


\subsection{La traducción en la trayectoria creadora de Carmen Martín Gaite}

La labor de Martín Gaite como traductora se entremezcla con su quehacer literario y con su faceta como crítica literaria. En el prólogo a El misterio de la carretera de Sintra, escribe sobre el proceso de escritura de la novela portuguesa, creada en un mano a mano entre Queirós y Ortigão, cuya primera entrega se publicó el 23 de julio de 1870, como si fuera una carta sin firma enviada al Diario de Notícias de Lisboa, que surgió cuando uno de ellos empezó a tomar notas sobre la marcha y que ambos continuaron escribiendo de un día para otro, improvisando, uno desde Leiría y otro desde Lisboa, como Ortigão contó en una ocasión (Martín Gaite 2011, 12-13).

Resulta comprensible que una obra concebida y emprendida en semejantes términos resulte incongruente, desordenada, híbrida, plagada de inexactitudes y repeticiones, desorbitada e inverosímil. Pero ya queda dicho que ninguno de los portugueses que leyó la primera entrega pudo abandonar la lectura hasta el final. Y el hecho de que hoy siga ocurriendo lo mismo es un tanto a favor de la innegable calidad de la obra, que fue imprimida en volumen al poco tiempo de su publicación por entregas y obtuvo un gran éxito. En el prólogo que escribió Eça para la segunda edición, en 1884, cuando ya era un escritor famoso, a pesar de juzgar con severidad la novela y llegar a decir que es "execrable», reconoce que significó un acto de rebeldía e independencia que puede considerarse como positivo. «En el Arte-dice- la indisciplina de los jóvenes, su resistencia a la imitación de las corrientes tradicionales, resulta indispensable para fortalecer la inventiva, el poder creador y la originalidad. Para ser ponderados, correctos e inmóviles, de sobra nos queda tiempo en la madurez» (Martín Gaite 2011, 13-14).

Como es habitual en sus críticas literarias, Martín Gaite escribe con honestidad y respeto sobre otros escritores (Fuentes del Río 2017). Del mismo modo que alude a los aspectos mejorables de las obras analizadas, también alaba y reconoce el arte de narrar de sus autores.

Pero, además, es que en El misterio de la carretera de Sintra hay otro tipo de aciertos, a mi entender todos debidos a la pluma de Eça de Queirós, que resplandecen a través del desmaño aparente de las apresuradas informaciones. Me atrevería a decir que no solo es una buena novela policíaca, sino que en algunos pasajes pueden rastrearse importantes gérmenes de una buena novela psicológica. Por ejemplo, en el tipo de la condesa -que, además, también se llama Luisa- hay un claro boceto de uno de los tipos femeninos mejor tratados posteriormente por la pluma de Eça de Queirós, la Luisa de El primo Basilio. Y hay también una intención de satirizar la novela folletinesca que hacía furor en la época, sin dejar de conservar, por ello, el esquema folletinesco, desdoblamiento que revela una madurez poco común (Martín Gaite 2011, 14-15). 
Esta idea de retroalimentación o de mutua influencia entre las distintas facetas creadoras de la autora, como crítica literaria, traductora, prologuista, guionista para series de televisión y cine, investigadora histórica, novelista y ensayista, es también compartida por otros investigadores. Por ejemplo, Teruel se centra en la relación entre su labor traductora y su creación literaria.

Entre la heterogeneidad de tradiciones narrativas que analizó -con títulos procedentes de la novela angloamericana, portuguesa, italiana, francesa, alemana y rusaestuvo siempre muy atenta en sus comentarios al rigor y esmero de las traducciones, hasta el punto de dedicar un artículo a «La ingrata condición del traductor. Bailar con la más fea» (Teruel 2006, 26).

En una nota a dicho artículo, Teruel $(2006,193)$ comenta que el manuscrito de la autora destinado a una disertación oral sobre la traducción es posterior a 1978 por las alusiones a su obra traducida y a su labor como traductora.

Considero de interés estas notas porque nos aproximan al taller de traducción de Carmen Martín Gaite, una de las facetas de su producción que no conviene descuidar por todo lo que podría revelar con respecto a su obra narrativa y ensayística: sirva de ejemplo la relación de significación y de contigüidad temporal que la redacción de Caperucita en Manhattan mantuvo con su versión de A grief observed de C. S. Lewis ${ }^{6}$ (Teruel en Martín Gaite 2006, 193).

Precisamente, respecto a la novela Caperucita en Manhattan, cuando Martín Gaite la escribe, ya había traducido el cuento clásico de Perrault, cuyos relatos había leído de niña, así que era conocedora de la historia original, que ella transforma en otro cuento. Además, mientras está traduciendo los cuentos de hadas de dicho escritor, también está elaborando su principal ensayo sobre la narración, en el que expone su poética o teoría literaria, El cuento de nunca acabar. Esta traducción y relectura de los relatos del autor francés le hace reflexionar sobre uno de los aspectos del quehacer literario tal como escribe en el citado ensayo; así, estas reflexiones las incluye en el capítulo «El gato con botas", título de uno de los cuentos y nombre de uno de los personajes de Perrault. Este hecho demuestra la influencia de la traducción en sus obras, en concreto, en uno de sus ensayos más importantes y en su propia teoría literaria, así como la interrelación y la mutua influencia entre sus distintas facetas creadoras.

6. Martín Gaite tradujo esta obra de C. S. Lewis al español bajo el título Una pena observada (Madrid: Trieste 1988), publicada después como Una pena en observación (Barcelona: Anagrama 1994). 
Al releer recientemente, con motivo de una traducción que me han encargado, los cuentos de hadas franceses, he venido a entender tardíamente por qué, cuando era niña, de entre todos los personajes de Perrault sentía una clara predilección por el Gato con Botas: porque es el único que inventa un cuento dentro del cuento, y gracias a eso consigue redimir a su amo del miserable porvenir a que estaba abocado por la doble circunstancia de su pobreza y de su orfandad (Martín Gaite 1988, 123).

En este sentido, Calvi $(1997,53)$ destaca de su labor como traductora el valor de «diálogo con el autor estudiado o traducido. Hay, en suma, una relación simbiótica entre la ficción y los demás trabajos de la autora». Por su parte, Martinell Gifre (1995) considera que existe una conexión entre las traducciones y los guiones para series de televisión y cine con su literatura.

[...] la presencia de Carmen Martín Gaite es visible en todos ellos, pues hay marcas que la delatan, y, lo que es más importante, que todo ese material ajeno sobre el que la autora trabaja se incorpora y nutre el suyo propio de un modo muy fructífero. Pensemos en su particular manera de ver el personaje de Celia, de las novelas de Elena Fortún; en su visión de Teresa de Ávila, o en su experimentación de la vaciedad de la actividad cotidiana a través de los textos de Ginzburg o de la relevancia del gesto imperceptible y del protagonista anodino de P. Levi (Martinell Gifre 1995, 19).

Su labor como traductora se enriquece y retroalimenta con sus otras facetas creadoras, sobre todo, con su labor como crítica literaria y novelista. La influencia de la traducción y de su trabajo como traductora, además, se refleja en su narrativa, no solo por las influencias literarias de los autores que leyó, sino también como motivo temático en su propia literatura. Un ejemplo es la novela Lo raro es vivir, cuya protagonista es investigadora histórica, ensayista y traductora, como Martín Gaite. Águeda Soler, que también está estudiando la vida de un personaje del siglo XVIII, compra un diccionario de catalán para traducir un artículo que contiene datos interesantes para su investigación y saborea el placer de descubrir palabras nuevas (Martín Gaite 2001, 127). Este personaje representa algunos de los aspectos que la autora considera requisitos imprescindibles para el trabajo del traductor, por ejemplo, el dominio del idioma. No en vano es una apasionada de la palabra y la lengua, como demuestra su afición por las metáforas. De hecho, aprende de niña el ruso por el empeño de su padre.

7. En la página siguiente de este libro, Martín Gaite $(1988,124)$ habla sobre los cuentos, con final feliz, a excepción de Caperucita Roja -salvo en alguna versión-, personaje y cuento de Perrault que ella reescribe en Caperucita en Manhattan.

La traducción en la obra de Carmen Martín Gaite Mónica FUENTES DEL RIOO 
Más tarde, sin embargo, esa penitencia -la única, a decir verdad, que me infligió mi padre- vino a convertirse en bendición del cielo, porque una licenciada en Historia del Arte lo tiene más bien crudo para ganarse la vida y en música nunca pasé de amateur. En cambio, traductores de ruso hay pocos buenos, y los pagan bien. Gracias a eso me pude ir de casa (Martín Gaite 2001, 136).

Estas últimas palabras de Águeda reflejan el conocimiento de Martín Gaite sobre la labor del traductor, así como acerca de las dificultades de dicha profesión en la sociedad actual. Su experiencia como traductora se refleja también en su práctica ficcional a través de las numerosas influencias literarias, que, además, se encuentran en el conjunto de su producción, algunas de las cuales son los autores procedentes de diferentes tradiciones literarias cuyas obras leyó y tradujo, y sobre los que escribió en sus críticas literarias, prólogos o reflexiones sobre la escritura -en ellas los pone como ejemplo del arte de narrar-. Natalia Ginzburg, Emily Brontë, Virginia Woolf, Italo Svevo, José María Eça de Queirós, Primo Levi... son algunos ejemplos. Además, con algunos de ellos comparte numerosas afinidades literarias y creadoras.

\section{CONCLUSIONES}

La traducción está presente en la obra de Carmen Martín Gaite, tanto en su teoría literaria, como en su práctica ficcional, ya que ambas se influyen mutuamente. La traducción conlleva para quien la practica una doble labor: por una parte, como lector de la obra original que se va a traducir; y, por otro lado, como escritor del nuevo texto en otra lengua. El traductor debe hacer una lectura minuciosa y exhaustiva para llevar a cabo la recreación de la obra, su versión, su interpretación a otro idioma. Por tanto, como el crítico, el traductor no solo la interpreta, sino que la recrea, aunque con diferencias. Por ese motivo, como asegura la autora, al traductor se le deben exigir determinados requisitos imprescindibles para realizar su trabajo de forma certera, algunos de los cuales coinciden con las cualidades del escritor.

Como traductora de libros del italiano, portugués, francés e inglés, y gran conocedora del castellano y de estos idiomas, Martín Gaite alaba el arte de traducir que reflejan algunas de las versiones que lee para elaborar sus críticas literarias. De la misma forma, censura las que considera malas prácticas en la traducción, pensando en el lector y en la importancia de ofrecerle una obra fiel al original. Además, su labor traductora se enriquece y retroalimenta con sus otras facetas creadoras, sobre todo, como crítica literaria y escritora de ficción. Su buen hacer contrasta con la opinión de la sociedad actual sobre la traducción, así como con el escaso esmero que se suele dedicar a este trabajo, según destaca la autora en su poética. 


\section{BIBLIOGRAFÍA}

BERASÁTEGUI, Blanca. 2000. «Es preferible equivocarse a callar». La Razón, 24 de julio de 2000: 28-29.

CALVI, Maria Vittoria. 1997. "Carmen Martín Gaite, en busca de interlocutor italiano». En Al encuentro de Carmen Martín Gaite, coord. por Emma Martinell Gifre. Barcelona: Universitat de Barcelona, 52-56.

CALVI, Maria Vittoria. 2007. «Introducción». En El libro de la fiebre, ed. por Maria Vittoria Calvi. Madrid: Cátedra, 9-74.

FERNÁNDEZ HOYOS, Sonia. 2014. «El legado ensayístico de Carmen Martín Gaite: los ensayos históricos o la lucidez de leer la historia». Espéculo. Revista de Estudios Literarios 52: 110122.

FUENTES DEL RíO, Mónica. 2017. «La concepción de la literatura en la obra de Carmen Martín Gaite: de la teoría literaria a la práctica ficcional. Un modelo comunicativo». Tesis doctoral. Universidad Complutense de Madrid.

FueNTES DEL Río, Mónica. 2019. Aprender a escribir con Carmen Martín Gaite. Madrid: Fragua.

GONZÁLEZ Couso, David. 2009. «Carmen Martín Gaite y su geografía literaria». Espéculo. Revista de Estudios Literarios 41.

JURADO MORALES, José. 2003. La trayectoria narrativa de Carmen Martín Gaite (1925-2000). Madrid: Gredos.

MARTÍN GAITE, Carmen. 1988. El cuento de nunca acabar. Barcelona: Anagrama.

MARTín GAITE, Carmen. 1993. Agua pasada. Barcelona: Anagrama.

MARTín GAITE, Carmen. 2001. Lo raro es vivir. Barcelona: Anagrama.

MARTín GaITE, Carmen. 2005. Visión de Nueva York. Madrid: Ediciones Siruela y Círculo de Lectores.

MARTín Gaite, Carmen. 2006. Tirando del hilo (artículos 1949-2000), ed. por José Teruel Benavente. Madrid: Ediciones Siruela.

MARTín GAITE, Carmen. 2011. «Prólogo» a Eça de Queirós y Ramalho Ortigão: El misterio de la carretera de Sintra. Barcelona: Acantilado, 7-15.

MARTINELL GIFRE, Emma. 1995. «Introducción». En Hilo a la cometa. La visión, la memoria y el sueño, ed. por Emma Martinell Gifre. Madrid: Espasa Calpe, 13-26.

MARTINELL GIFRE, Emma. 1997. «Bibliografía de Carmen Martín Gaite». En Al encuentro de Carmen Martín Gaite, coord. por Emma Martinell Gifre. Barcelona: Universitat de Barcelona, 77-90.

MARTINELL GIFRE, Emma. 1998. «Entrevista con Carmen Martín Gaite». Espéculo. Revista de Estudios Literarios 8.

MARTINELL GIFRE, Emma. 1999. «Introducción». En Cuéntame, ed. por Emma Martinell Gifre. Madrid: Espasa Calpe, 9-46.

ROMERO LÓPEZ, Dolores. 2002. "Primeros textos publicados de Carmen Martín Gaite en la revista Trabajos y días (Salamanca, 1946-1951)». Signa 11: 239-256.

TERUEL BENAVENTE, José. 2006. "Carmen Martín Gaite, articulista». En Tirando del hilo (artículos 1949-2000), ed. por José Teruel Benavente. Madrid: Ediciones Siruela, 19-31.

La traducción en la obra de Carmen Martín Gaite Mónica FUENTES DEL RIOO 
